\title{
Diabetes mellitus and hypertension have comparable adverse effects on health-related quality of life
}

\author{
Tamara Poljičanin ${ }^{1 *}$, Dea Ajduković1, Mario Šekerija', Mirjana Pibernik-Okanović1 ${ }^{1}$ Željko Metelko', \\ Gorka Vuletić Mavrinac ${ }^{2}$
}

\begin{abstract}
Background: We aimed to assess health-related quality of life (HRQoL) among people with diabetes or hypertension, estimate the effect of cardiovascular comorbidities on HRQoL as well as compare HRQoL in these groups with that of healthy individuals.

Methods: A total of 9,070 respondents aged 18 years and over were assessed for HRQoL. Data were obtained from the Croatian Adult Health Survey. Respondents were divided into five groups according to their medical history: participants with hypertension (RR), hypertension and cardiovascular comorbidities (RR+), diabetes mellitus (DM), diabetes and cardiovascular comorbidities (DM+) and participants free of these conditions (healthy individuals, HI). HRQoL was assessed on 8 dimensions of the SF-36 questionnaire.

Results: Participants with diabetes and those with hypertension reported comparably limited $(p>0.05) \mathrm{HRQOL}$ in all dimensions of SF-36, compared with healthy individuals $(p<0.05)$. If cardiovascular comorbidities were present, both participants with diabetes and participants with hypertension had lower results on all SF-36 scales ( $p>0.05)$ than participants without such comorbidities $(p<0.05)$. The results remained after adjustment for sociodemographic variables (age, sex, employment, financial status and education).

Conclusion: Diabetes and hypertension seem to comparably impair HRQoL. Cardiovascular comorbidities further reduce HRQoL in participants with both chronic conditions. Future research of interventions aimed at improving these participants' HRQoL is needed.
\end{abstract}

\section{Background}

One of the most important goals of all health interventions is to improve the quality of life of persons affected by disease [1]. In the domain of physical health and illness, quality of life refers to participant's self-evaluation of health or on their perceived functional status and well-being [2]. In chronic conditions such as hypertension and diabetes, health-related quality of life (HRQoL) is an especially important outcome, given their lifelong nature and the need for daily self-management.

HRQoL has been found to be poorer in diabetic participants than in the general population [1,3], especially in the domains of self perceived physical health, while findings on domains of psychosocial functioning vary

\footnotetext{
* Correspondence: tamara.poljicanin@idb.hr

${ }^{1}$ Vuk Vrhovac University Clinic, Zagreb, Croatia
}

between studies [4-7]. Hypertension has also been shown to be associated with negative outcomes in HRQoL, especially in the domain of subjectively perceived general health, although its impact on HRQoL is usually less adverse than that of other chronic diseases $[4,8]$.

Although studies comparing the effects of different chronic diseases generally point to a conclusion that hypertension has less adverse effects on HRQoL than diabetes, the magnitude and profile of differences between diabetic and hypertensive participants in HRQoL have not been determined as yet [9-11].

Epidemiological research of HRQoL in Croatia has so far been conducted only for the general population [12], while comprehensive research of HRQoL in Croatian participants with chronic conditions is still lacking. As

(c) 2010 Poljičanin et al; licensee BioMed Central Ltd. This is an Open Access article distributed under the terms of the Creative 
diabetes and hypertension are among the chronic diseases that affect the largest number of individuals and lead to severe complications, the present study was aimed at determining HRQoL in diabetic and hypertensive participants, and to examining the effects of cardiovascular comorbidities on HRQoL in these chronic conditions.

\section{Methods}

\section{Participants}

This survey was a part of the Croatian Adult Health Survey (CAHS), a cross-sectional field survey conducted by trained health care professionals in 2003. Data collected in this study provided a comprehensive assessment of health of Croatian residents, including their HRQoL, access to and use of health care services, health status and determinants such as smoking, physical activity, nutrition and alcohol use. The study was approved by the Research Ethics Committee, Medical School, University of Zagreb, grant number 04-1060-2006. The design of the CAHS is described in more detail elsewhere [13].

\section{Sampling}

A total of 9,070 respondents aged 18 years and over were assessed for HRQoL.

Respondents were divided into 5 groups: participants with hypertension (RR) (I10; ICD-10), participants with hypertension and cardiovascular co-morbidities $(\mathrm{RR}+)$, participants with diabetes mellitus (DM) (E10-E14; ICD10), participants with diabetes and cardiovascular comorbidities $(\mathrm{DM}+)$ and individuals without these conditions, i.e. healthy individuals (HI). Cardiovascular comorbidities were defined as self-reported history of angina (I20; ICD-10), myocardial infarction (I25.2; ICD10), heart insufficiency (I50; ICD-10) or stroke (I61, I63, I64; ICD-10). Participants with both hypertension and diabetes were classified as DM+.

\section{Instruments}

HRQoL was assessed by SF-36, the Medical Outcome Study short-form health survey [14-16]. The Croatian version of the SF-36 questionnaire was prepared using a standard translation procedure, followed by a pilot study carried out in 1998 [12]. Psychometric characteristics of this instrument have shown its adequate reliability and validity [17].

The questionnaire contains 36 items integrated in multi-item scales measuring eight generic health concepts: physical functioning (PF), social functioning (SF), role physical (RP), bodily pain (BP), mental health $(\mathrm{MH})$, role emotional (RE), vitality $(\mathrm{VT})$, and general health $(\mathrm{GH})$.

Scoring included transformation of raw scores for each subscale to a 0-100 scale, with higher scores representing better quality of life.

\section{Statistical analysis}

All statistical analyses were performed using SAS (version 9.1.3). Descriptive analysis included calculations of means, 95\% confidence intervals (CI) of means and frequencies of categorical variables. Distributions of categorical sociodemographic predictors were compared using chi-square tests, with a downward adjustment of statistical significance for multiple comparisons. The corrected level of significance was obtained using Bonferroni correction, i.e. by dividing the defined $\mathrm{p}$ value $(0.05)$ with the number of comparisons made $(n=10)$. The adjusted significant $\mathrm{p}$ value for multiple comparison of categorical predictors was thus less than 0.005 ( $p<0.005)$. The level of significance of correlation between variables and the correlation trend were analysed by Pearson Test. The differences between groups and the impact of categorical sociodemographic variables were estimated by MANOVA. Continuous sociodemographic variables were controlled for by MANCOVA. All post-hoc comparisons were performed by Scheffe test. Statistical significance was defined as $\mathrm{p}$ value less than 0.05 ( $\mathrm{p}<$ 0.05).

\section{Results}

Participants' sociodemographic characteristics are presented in Table 1. There were statistically significant differences among different groups of participants and healthy individuals in age $(\mathrm{p}<0.001)$, level of education, employment status and self-evaluation of financial status ( $\mathrm{p}<0.001)$. Healthy individuals were younger, better educated, more often employed and of better financial status than participants with hypertension and/or diabetes. Among participants with hypertension and/or diabetes, those with cardiovascular comorbidities (DM+ and $\mathrm{RR}+$ ) were older, less educated, less often employed and of worse self-assessed financial status than participants without these comorbidities (DM and RR) ( $\mathrm{p}<$ 0.001). The only insignificant differences were those for self-assessed financial status among participants with diabetes compared with participants who had cardiovascular comorbidities (DM vs DM+ and DM vs RR+). Participants with a matching status of comorbidities (RR vs $\mathrm{DM}$ and $\mathrm{RR}+\mathrm{vs} \mathrm{DM}+$ ) did not differ in sociodemographic predictors. All groups consisted of more women than men. There was a statistically significant difference in sex $(\mathrm{p}<0.001)$ between the groups without complications (DM and RR) with predomination of women with hypertension, while the difference was insignificant $(\mathrm{p}=$ $0.073)$ between the groups with complications $(\mathrm{DM}+$ and $\mathrm{RR}+$ ).

Data on HRQoL are presented in Table 2. All dimensions of SF-36 were significantly lower among participants with diabetes and/or hypertension than among healthy individuals $(\mathrm{p}<0.001)$. Groups with 
Table 1 Sociodemographic characteristics of the studied groups

\begin{tabular}{|c|c|c|c|c|c|c|c|c|}
\hline & & $\mathrm{HI}(\mathrm{N}=5.043)$ & $\mathrm{RR}(\mathrm{N}=1.490)$ & $\mathrm{RR}+(\mathrm{N}=1.564)$ & $\mathrm{DM}(\mathrm{N}=231)$ & $\mathrm{DM}+(\mathrm{N}=742)$ & $p$ & $\begin{array}{l}\text { significant } \\
\text { differences }^{b}\end{array}$ \\
\hline$\overline{\mathrm{Age}^{a}}$ & & $\begin{array}{c}46.5 \\
(46.1-47.0)\end{array}$ & $\begin{array}{c}60.1 \\
(59.4-60.8)\end{array}$ & $\begin{array}{c}65.3 \\
(64.6-65.9)\end{array}$ & $\begin{array}{c}60.0 \\
(58.4-61.7)\end{array}$ & $\begin{array}{c}65.7 \\
(64.9-66.5)\end{array}$ & $<0.001$ & $\begin{array}{c}\text { RR\&RR+, RR\&DM+, } \\
\text { DM\&DM+, DM\&RR+, } \\
\text { HI\&all other groups }\end{array}$ \\
\hline \multirow[t]{2}{*}{ Gender } & Male & $32.8 \%$ & $29.9 \%$ & $28.7 \%$ & $44.6 \%$ & $32.3 \%$ & $<0.001$ & $\begin{array}{l}\text { DM\&DM+, DM\&RR+, RR } \\
\& D M, R R+\& H I, D M \& H I\end{array}$ \\
\hline & Female & $67.2 \%$ & $70.1 \%$ & $71.3 \%$ & $55.4 \%$ & $67.7 \%$ & & \\
\hline \multirow[t]{4}{*}{$\begin{array}{l}\text { Level of } \\
\text { education }\end{array}$} & $\begin{array}{l}\text { Unfinished } \\
\text { primary } \\
\text { school } \\
\end{array}$ & $9.8 \%$ & $24.2 \%$ & $31,1 \%$ & $16.0 \%$ & $30.7 \%$ & $<0.001$ & $\begin{array}{c}\text { RR\&RR+, RR\&DM+, } \\
\text { DM\&DM+, DM\&RR+, } \\
\text { HI\&all other groups } \\
\end{array}$ \\
\hline & $\begin{array}{l}\text { Primary } \\
\text { school }\end{array}$ & $20.1 \%$ & $26.9 \%$ & $28.8 \%$ & $28.6 \%$ & $27.8 \%$ & & \\
\hline & $\begin{array}{l}\text { High school } \\
\text { or similar }\end{array}$ & $53.5 \%$ & $37.4 \%$ & $31.2 \%$ & $43.3 \%$ & $32.4 \%$ & & \\
\hline & $\begin{array}{l}\text { College or } \\
\text { University }\end{array}$ & $16.6 \%$ & $11.5 \%$ & $8,9 \%$ & $12.1 \%$ & $9.1 \%$ & & \\
\hline \multirow[t]{2}{*}{ Employed } & Yes & $44.0 \%$ & $22.3 \%$ & $11.9 \%$ & $21.2 \%$ & $10.4 \%$ & $<0.001$ & $\begin{array}{l}\text { RR\&RR+, RR\&DM+, } \\
\text { DM\&DM+, DM\&RR+, } \\
\text { HI\&all other groups }\end{array}$ \\
\hline & No & $56.0 \%$ & $77.7 \%$ & $88.1 \%$ & $78.8 \%$ & $89.6 \%$ & & \\
\hline \multirow{3}{*}{$\begin{array}{l}\text { Self- } \\
\text { evaluation of } \\
\text { financial } \\
\text { status }\end{array}$} & $\begin{array}{l}\text { Poorer than } \\
\text { average }\end{array}$ & $36.8 \%$ & $45.0 \%$ & $54.7 \%$ & $45.4 \%$ & $53.0 \%$ & $<0.001$ & $\begin{array}{c}\text { RR\&RR+, RR\&DM+, } \\
\text { RR\&HI, RR+\&HI, DM } \\
+\& H I\end{array}$ \\
\hline & Average & $50.2 \%$ & $45.5 \%$ & $39.3 \%$ & $45.9 \%$ & $40.4 \%$ & & \\
\hline & $\begin{array}{l}\text { Better than } \\
\text { average }\end{array}$ & $13.0 \%$ & $9.5 \%$ & $6.0 \%$ & $8.7 \%$ & $6.6 \%$ & & \\
\hline
\end{tabular}

Data are presented as proportion (\%) unless noted otherwise; ${ }^{a}$ Mean ( $\pm 95 \%$ confidence interval) ${ }^{\mathrm{b}}$ Pairs with significant differences between groups; post-hoc analysis with downward adjustment for multiple comparison; Abbreviations: HI - healthy individuals, RR - participants with hypertension, RR+ - hypertension and other cardiovascular comorbidities, DM - diabetes mellitus, DM+ - diabetes mellitus and cardiovascular comorbidities

complications (DM+ and $\mathrm{RR}+$ ) had poorer HRQoL on all dimensions of SF-36 in comparison with the healthy individuals $(\mathrm{p}<0.001)$ as well as those without complications (DM and RR) ( $<<0.05)$.

The studied groups differed significantly in all dimensions of SF-36 ( $p<0.001)$. In post-hoc analyses we found that, regardless of diabetes or hypertension status, participants with comorbidities had comparable, significantly poorer HRQoL than participants without comorbidities ( $\mathrm{p}$ $<0.001)$. Age showed small to medium correlations with all dimensions of HRQoL ( $\mathrm{p}<0.05$ ); when controlled for, differences between the groups of participants with (DM+ and $R R+$ ) and those without comorbidities (DM and RR) remained significant $(\mathrm{p}<0.001)$, as well as differences between healthy individuals ( $\mathrm{HI}$ ) and all other groups (DM, DM+, RR, RR+). Adjusted data on HRQoL are also presented in Table 2. Unemployment, lower self-evaluated financial status and lower level of education were associated with worse self-assessments of HRQoL in all subgroups of participants ( $\mathrm{p}<0.05)$.

Women had consistently lower scores on all dimensions of SF-36 ( $\mathrm{p}<0.001)$, indicating poorer HRQoL. In the groups without complications (DM and RR), stratified analysis according to sex revealed poorer social functioning and more bodily pain $(\mathrm{p}<0.05)$ in women with diabetes (DM) than in women with hypertension (RR), while all other differences were insignificant $(p>0.05)$. There were no significant differences between diabetic (DM) and hypertensive (RR) men in any of the SF components.

All differences in HRQoL between participants with and without comorbidities were clinically relevant, as they were greater than 5 points on a $0-100$ scale which is found to be clinically significant [18]. Impairments in HRQoL dimensions of participants with comorbidities were most 
Table 2 The unadjusted and adjusted HRQoL indicators in the studied groups.

\begin{tabular}{|c|c|c|c|c|c|c|}
\hline & $\mathrm{HI}(\mathrm{N}=5,043)$ & $R R(N=1,490)$ & $R R+(N=1,564)$ & $\mathrm{DM}(\mathrm{N}=231)$ & $\mathrm{DM}+(\mathrm{N}=742)$ & $p^{a}$ \\
\hline \multirow[t]{2}{*}{$\mathrm{PF}$} & $81.5(80.9-82.2)$ & $66.6(65.2-68.0)$ & $47.8(46.3-49.2)$ & $65.1(61.5-68.7)$ & $49.9(47.8-52.0)$ & $<0.001$ \\
\hline & 78.1 (76.8-79.5) & $67.8(66.0-69.7)$ & $51.7(49.7-53.7)$ & $69.4(65.4-73.4)$ & $57.3(54.6-60.0)$ & \\
\hline \multirow[t]{2}{*}{$\mathrm{RP}$} & $77.5(76.4-78.5)$ & $58.1(55.9-60.3)$ & $33.5(31.4-35.6)$ & $56.1(50.2-61.9)$ & $35.9(32.7-39.1)$ & $<0.001$ \\
\hline & $73.3(71.1-75.5)$ & $60.3(57.3-63.3)$ & $38.1(34.8-41.3)$ & $61.1(54.6-67.7)$ & $43.4(39.0-47.8)$ & \\
\hline \multirow[t]{2}{*}{$\mathrm{BP}$} & $74.5(73.7-75.3)$ & $62.1(60.7-63.6)$ & $48.5(47.1-50.0)$ & $58.7(54.9-62.5)$ & $49.4(47.2-51.6)$ & $<0.001$ \\
\hline & 72.8 (71.2-74.3) & $65.5(63.4-67.6)$ & $52.7(50.3-57.0)$ & $62.9(58.3-67.6)$ & $54.0(50.9-57.1)$ & \\
\hline \multirow[t]{2}{*}{$\mathrm{GH}$} & $64.2(63.6-64.8)$ & $51.6(50.6-52.6)$ & $40.2(39.2-41.1)$ & $49.0(46.3-51.7)$ & $39.2(37.8-40.6)$ & $<0.001$ \\
\hline & $62.9(61.8-64.0)$ & $53.2(51.7-54.7)$ & $43.7(42.1-45.3)$ & $52.7(49.5-55.9)$ & $41.7(39.6-43.9)$ & \\
\hline \multirow[t]{2}{*}{$\mathrm{VT}$} & $60.7(60.1-61.2)$ & $53.2(52.2-54.2)$ & $39.8(38.7-40.9)$ & $51.4(48.5-54.3)$ & $41.3(39.7-43.0)$ & $<0.001$ \\
\hline & $59.1(57.9-60.2)$ & $55.4(53.9-57.0)$ & $44.4(42.7-46.1)$ & $55.0(51.7-58.4)$ & $46.5(44.2-48.7)$ & \\
\hline \multirow[t]{2}{*}{ SF } & $82.0(81.4-82.7)$ & $74.4(73.1-75.6)$ & $58.7(57.2-60.2)$ & $69.2(65.6-72.8)$ & $59.8(57.6-61.9)$ & $<0.001$ \\
\hline & $79.2(77.8-80.6)$ & 76.1 (74.2-78.0) & $62.7(60.6-64.8)$ & $73.9(69.8-78.1)$ & $64.7(61.9-67.4)$ & \\
\hline \multirow[t]{2}{*}{ RE } & 79.9 (78.9-80.9) & $69.3(67.1-71.4)$ & $51.4(49.1-53.7)$ & $70.4(64.9-76.0)$ & $51.5(48.1-54.9)$ & $<0.001$ \\
\hline & 76.6 (74.3-78.8) & 72.6 (69.5-75.7) & $57.1(53.7-60.5)$ & 74.7 (67.9-81.4) & $58.8(54.2-63.3)$ & \\
\hline \multirow[t]{2}{*}{$\mathrm{MH}$} & $68.3(67.8-68.8)$ & $62.5(61.5-63.4)$ & $52.8(51.7-53.8)$ & $60.6(58.1-63.2)$ & $53.7(52.1-55.3)$ & $<0.001$ \\
\hline & $66.8(65.7-67.8)$ & $64.0(62.6-65.5)$ & $57.8(56.2-59.4)$ & $63.4(60.2-66.5)$ & $58.1(56.0-60.2)$ & \\
\hline
\end{tabular}

Data are presented as mean ( \pm 95\% confidence interval); adjusted results are in italic format; ${ }^{\text {a }}$ post-hoc analysis showed significant differences between RR\&RR+ RR\&DM+, DM\&DM+, DM\&RR+ and HI\& all other groups (RR, RR+, DM, DM+) in all SF-36 dimensions; Scheffe test, p < 0.001; Abbreviations: HI - healthy individuals, RR - participants with hypertension, RR+ - hypertension and other cardiovascular comorbidities, DM - diabetes mellitus, DM+ - diabetes mellitus and cardiovascular comorbidities, PF - physical functioning, RP - role physical, BP - bodily pain, GH - general health, VT - vitality, SF - social functioning, RE - role emotional, $\mathrm{MH}$ - mental health.

pronounced in the domain of physical roles $(\mathrm{RP})$, social functioning (SF) and physical functioning (PF).

\section{Discussion}

Our results suggest that diabetes and hypertension have comparably negative effects on HRQoL, which supports the conclusion that both conditions impose similar self perceived limitations in physical and mental functioning. However, available literature [1] suggests that diabetes in its early stages has no impact on perceived HRQoL of the affected individuals, while our study found lower scores on the majority of SF-36 dimensions, even in participants without cardiovascular comorbidities. This might suggest that assessing HRQoL may be beneficial even in the early stages of treatment for diabetes and hypertension.

In our study all dimensions of HRQoL were poorer in people with diabetes and hypertension (DM and RR), as well as in participants with cardiovascular complications (DM+ and $\mathrm{RR}+$ ), compared with healthy individuals (HI). However, our data did not include information on possible non-vascular comorbidities, such as retinopathy, nephropathy or musculoskeletal disease, which have been found to be important predictors of HRQoL in diabetes $[1,2,5]$. It is likely that some individuals who had been classified into the groups without cardiovascular comorbidities of hypertension or diabetes had other comorbidities that potentially reduced their HRQoL. On the other hand, even in the absence of any comorbidities, a mere perception of being chronically ill and thus frailer than a healthy person may also detrimentally affect participant's HRQoL [19,20].

We also observed that cardiovascular comorbidities had a particularly negative impact on HRQoL in these two chronic diseases. This is in line with previous research which has found that the presence of macrovascular complications was a very important factor that comparably limited participants' HRQoL [1,2] to a clinically significant extent [18] in both hypertension and diabetes. Cardiovascular comorbidities are thought to debilitate physical functioning to a higher degree than hypertension or diabetes alone. This can be substantiated by profiles of particular SF-36 scales, as selfreported well-being in participants with comorbidities has been shown to be poorest with respect to physical functioning (RP and PF).

Previous studies have reported that diabetes and hypertension negatively affect participants' HRQoL $[4,5,21]$, and that heart disease worsened these participants' HRQoL even further [6,22-27]. However, other studies have yielded conflicting results on the severity of impact of diabetes and hypertension on HRQoL [28,29], without demonstrating whether the degree of impact of cardiovascular comorbidities in these two conditions is comparable.

Between-group comparisons of demographic characteristics (level of education, employment status and selfevaluation of financial status) in paired participant groups (DM vs $\mathrm{RR}$ and $\mathrm{DM}+\mathrm{vs} \mathrm{RR}+$ ) did not reveal statistically significant differences. Although these 
demographic factors influence HRQoL, their effect may be presumed to have been comparable in the groups with complications (DM+ and $\mathrm{RR}+$ ), as well as in those without complications (DM and RR). Taking into account the differences in sex between the groups without complications (DM and RR), we analysed both sexes separately and found differences in social functioning and bodily pain, but only in women. In view of these results and of the fact that HRQoL was similarly affected in the pairs of groups with complications $(\mathrm{DM}+$ and $R R+$ ) and in those without them (DM and RR) even after age was controlled for, we conclude that the observed differences are attributable to chronic conditions rather than to possible sociodemographic confounders analysed in this study.

Our results confirm previous reports of adverse impacts of diabetes and hypertension on participants' well-being and functioning. The novelty of our study is that it shows these effect sizes are comparable. This is a useful finding for clinical practice, particularly in the early treatment of diabetes and hypertension, at which point improvement in self-management and consequently HRQoL is still possible. Our results also contribute to transcultural research of HRQoL in diabetes and hypertension, as research on this issue in transitional countries has been scarce.

Limitations of our study include the self-reported nature of the CAHS data, and that more detailed information on disease duration, adherence to treatment, and non-vascular concomitant diseases were unavailable. However, all data were collected by trained medical professional, which could provide some certainty that medical conditions studied were recognized and classified properly.

\section{Conclusions}

Our results showed an adverse impact of both diabetes and hypertension on participants' well-being and functioning, adding to current knowledge by the finding that the effect sizes are comparable, at least in the Croatian adult population. This could be useful in clinical practice, particularly in early treatment of diabetes and hypertension, at which point improving self-management and consequently HRQoL is still possible. We also found that cardiovascular comorbidities have a marked negative impact on HRQoL in people with both these conditions.

Early recognition of participants with these chronic diseases might therefore be considered to be of importance, not only in clinical disease management, but also in participant education and empowerment aimed at improving their HRQoL. Further research on appropriate interventions aimed at HRQoL of these participants is needed.

\section{Abbreviations}

HRQOL: health-related quality of life; DM: diabetes mellitus; DM+: diabetes mellitus and cardiovascular comorbidities; RR: hypertension; RR+: hypertension and other cardiovascular comorbidities; PF: physical functioning; SF: social functioning; RP: role physical; BP: bodily pain; $\mathrm{MH}$ : mental health; RE: role emotional; VT: vitality; GH: general health

\section{Acknowledgements}

This manuscript is prepared within the project of the Ministry of Science, Education and Sports, Grant No. 108-1080135-0264. We thank Professors Josipa Kern and Anja Jazbec for statistical advising. We also thank Lovorka Perković for copyediting the manuscript and Dr Kristina Fišter for editorial consultation.

\section{Author details}

${ }^{1}$ Vuk Vrhovac University Clinic, Zagreb, Croatia. ${ }^{2}$ Andrija Štampar School of Public Health, Medical School, University of Zagreb, Zagreb, Croatia.

\section{Authors' contributions}

TP participated in study design, drafted the manuscript and performed the statistical analysis. DA and MS prepared the data for statistical analysis and participated in the preparation of the manuscript. MPO and ZM participated in study design, and revised the manuscript critically. GVM was included in conduction of Croatian Adult Health Survey (CAHS) and participated in study design. All authors have read and approved the final version of the manuscript.

\section{Competing interests}

The authors declare that they have no competing interests.

\section{Received: 2 June 2009}

Accepted: 13 January 2010 Published: 13 January 2010

\section{References}

1. Rubin RR, Peyrot M: Quality of life and diabetes. Diabetes Metab Res Rev 1999, 15(3):205-218.

2. Wandell PE: Quality of life of patients with diabetes mellitus. An overview of research in primary health care in the Nordic countries. Scand J Prim Health Care 2005, 23(2):68-74.

3. Saito I, Inami F, Ikebe T, Moriwaki C, Tsubakimoto A, Yonemasu K, Ozawa H: Impact of diabetes on health-related quality of life in a population study in Japan. Diabetes Res Clin Pract 2006, 73(1):51-57.

4. Stewart AL, Greenfield S, Hays RD, Wells K, Rogers WH, Berry SD, McGlynn EA, Ware JE Jr: Functional status and well-being of patients with chronic conditions. Results from the Medical Outcomes Study. JAMA 1989, 262(7):907-913.

5. Wandell PE, Brorsson B, Aberg H: Quality of life in diabetic patients registered with primary health care services in Sweden. Scand J Prim Health Care 1997, 15(2):97-102.

6. Bardage C, Isacson DG: Hypertension and health-related quality of life. an epidemiological study in Sweden. J Clin Epidemiol 2001, 54(2):172-181.

7. Pibernik-Okanovic M, Szabo S, Metelko Z: Quality of Life in Diabetic, Otherwise III and Healthy Persons. Diabetol Croat 1996, 25(3):117-121.

8. Lawrence WF, Fryback DG, Martin PA, Klein R, Klein BE: Health status and hypertension: a population-based study. J Clin Epidemiol 1996, 49(11):1239-1245.

9. Kempen Gl, Ormel J, Brilman El, Relyveld J: Adaptive responses among Dutch elderly: the impact of eight chronic medical conditions on healthrelated quality of life. Am J Public Health 1997, 87(1):38-44.

10. Testa MA, Simonson DC: Measuring quality of life in hypertensive patients with diabetes. Postgrad Med J 1988, 64(Suppl 3):50-58, discussion 90-52.

11. Lyons RA, Lo SV, Littlepage BN: Comparative health status of patients with 11 common illnesses in Wales. J Epidemiol Community Health 1994, 48(4):388-390.

12. Juresa V, Ivankovic D, Vuletic G, Babic-Banaszak A, Srcek I, Mastilica M, Budak A: The Croatian Health Survey-SF-36: I. General quality of life assessment. Coll Antropol 2000, 24(1):69-78. 
13. Vuletic S, Polasek O, Kern J, Strnad M, Baklaic Z: Croatian Adult Health Survey-a tool for periodic cardiovascular risk factors surveillance. Coll Antropol 2009, 33(Suppl 1):3-9.

14. Ware JE Jr, Sherbourne CD: The MOS 36-item short-form health survey (SF-36). I. Conceptual framework and item selection. Med Care 1992, 30(6):473-483.

15. McHorney CA, Ware JE Jr, Raczek AE: The MOS 36-Item Short-Form Health Survey (SF-36): II. Psychometric and clinical tests of validity in measuring physical and mental health constructs. Med Care 1993, 31(3):247-263.

16. Kaplan SH: Patient reports of health status as predictors of physiologic health measures in chronic disease. J Chronic Dis 1987, 40(Suppl 1):27S-40S.

17. Maslic Sersic D, Vuletic G: Psychometric evaluation and establishing norms of Croatian SF-36 health survey: framework for subjective health research. Croat Med J 2006, 47(1):95-102.

18. Ware JE: SF-36 health survey: manual and interpretation guide Lincoln, R.I. QualityMetric; Boston, Mass.: Health Assessment Lab 2000.

19. Irvine MJ, Garner DM, Olmsted MP, Logan AG: Personality differences between hypertensive and normotensive individuals: influence of knowledge of hypertension status. Psychosom Med 1989, 51(5):537-549.

20. Bloom JR, Monterossa S: Hypertension labeling and sense of well-being. Am J Public Health 1981, 71(11):1228-1232.

21. Aalto AM, Uutela A, Kangas T: Health behaviour, social integration, perceived health and dysfunction. A comparison between patients with type I and II diabetes and controls. Scand J Soc Med 1996, 24(4):272-281.

22. Maddigan SL, Feeny DH, Johnson JA: Health-related quality of life deficits associated with diabetes and comorbidities in a Canadian National Population Health Survey. Qual Life Res 2005, 14(5):1311-1320.

23. Gulliford MC, Mahabir D: Relationship of health-related quality of life to symptom severity in diabetes mellitus: a study in Trinidad and Tobago. $J$ Clin Epidemiol 1999, 52(8):773-780.

24. de Visser CL, Bilo HJ, Groenier KH, de Visser W, Jong Meyboom-de B: The influence of cardiovascular disease on quality of life in type 2 diabetics. Qual Life Res 2002, 11(3):249-261.

25. Hahl J, Hamalainen $H$, Sintonen $H$, Simell T, Arinen S, Simell O: Healthrelated quality of life in type 1 diabetes without or with symptoms of long-term complications. Qual Life Res 2002, 11(5):427-436.

26. Aydemir O, Ozdemir C, Koroglu E: The impact of co-morbid conditions on the SF-36: a primary-care-based study among hypertensives. Arch Med Res 2005, 36(2):136-141.

27. Lahad A, Yodfat Y: Impact of comorbidity on well-being in hypertension: case control study. J Hum Hypertens 1993, 7(6):611-614.

28. Alonso J, Ferrer M, Gandek B, Ware JE, Aaronson NK, Mosconi P, Rasmussen NK, Bullinger M, Fukuhara S, Kaasa S, et al: Health-related quality of life associated with chronic conditions in eight countries: Results from the International Quality of Life Assessment (IQOLA) Project. Qual Life Res 2004, 13(2):283-298.

29. Smith DW: The population perspective on quality of life among Americans with diabetes. Qual Life Res 2004, 13(8):1391-1400.

\section{Pre-publication history}

The pre-publication history for this paper can be accessed here:http://www. biomedcentral.com/1471-2458/10/12/prepub

\section{doi:10.1186/1471-2458-10-12}

Cite this article as: Poljičanin et al:: Diabetes mellitus and hypertension have comparable adverse effects on health-related quality of life. BMC Public Health 2010 10:12.

\section{Submit your next manuscript to BioMed Central and take full advantage of:}

- Convenient online submission

- Thorough peer review

- No space constraints or color figure charges

- Immediate publication on acceptance

- Inclusion in PubMed, CAS, Scopus and Google Scholar

- Research which is freely available for redistribution

Submit your manuscript at www.biomedcentral.com/submit
Biomed Central 